Research Article

\title{
Complex Processing of Adsorbent Used in the Purification of Hydrogen-Containing Gas
}

\author{
Sukhrob Ibodullaev ${ }^{1}$, Nurkhon Isaeva ${ }^{2}$, Rustam Khodjiev ${ }^{3}$, Elena Mirzaeva ${ }^{4}$, \\ Dilnoza Turdieva ${ }^{2}$, Shukhrat Gulomov ${ }^{2}$, Shavkat Mamatkulov1,*
}

\author{
${ }^{1}$ Institute of Material Science of the Uzbekistan Academy of Sciences, Ch. Aytmatov str.2B, Tashkent \\ 100084, Uzbekistan. \\ ${ }^{2}$ Center for Advanced Technologies, University str.7, Tashkent 100174, Uzbekistan. \\ ${ }_{3}^{3}$ Bukhara Petroleum Refinery Plant Unitary Enterprise, Karaul-bazar, street Mustakillik 1, Bukhara \\ Region 200900, Uzbekistan. \\ ${ }^{4}$ Almalyk Branch of the National Research Technological University "MiSIS", Uzbekistan.
}

Received: 27th September 2021; Revised: 29th October 2021; Accepted: 30 ${ }^{\text {th }}$ October 2021

Available online: $9^{\text {th }}$ November 2021; Published regularly: March 2022

\section{Abstract}

The problems of processing spent adsorbents with a high concentration of chemisorbed chlorine-containing compounds for their reuse are studied in this article. The genesis of the phase composition and morphology at all technological stages of thermochemical regeneration of the spent adsorbent - Axstrap-860 by means of alkaline modification with a combined solution of sodium and potassium hydroxides has been tested by diffractometry and elemental analysis. The results show that the formation of a layer with an increased concentration of alkali metals in the form of the corresponding carbonates and $\mathrm{NaOH}$ on the surface of the granules and in the volume of sodium and potassium aluminates provides adsorption of $\mathrm{HCl}$, which are slightly inferior to the fresh adsorbent. The conditions for the removal of halogen-containing substances from technogenic raw materials with the subsequent isolation of useful products have been optimized: (1) crystalline $\mathrm{NaCl}$ intended for the preparation of electrolyte for electrode boilers and steam generators; (2) a mixture of chlorides and hydroxochlorides of aluminum tested in the process of coagulation purification of turbid natural and waste waters; (3) pseudoboehmite for the production of an adsorbent-desiccant and the synthesis of magnesium-aluminum spinel using the technology of destructionepitaxial transformation, and a promising carrier for catalysts for steam reforming of hydrocarbons.

Copyright (C 2021 by Authors, Published by BCREC Group. This is an open access article under the CC BY-SA License (https://creativecommons.org/licenses/by-sa/4.0).

Keywords: Adsorbent; Catalyst carrier; Oil refining; Regeneration of catalysts; Hydrogen

How to Cite: S. Ibodullaev, N. Isaeva, R. Khodjiev, E. Mirzaeva, D. Turdieva, S. Gulomov, S. Mamatkulov (2022). Complex Processing of Adsorbent Used in the Purification of Hydrogen-Containing Gas. Bulletin of Chemical Reaction Engineering \& Catalysis, 17(1), 32-45 (doi: 10.9767/bcrec.17.1.12366.32-45)

Permalink/DOI: https://doi.org/10.9767/bcrec.17.1.12366.32-45

\section{Introduction}

The oil and gas processing industry along with the petrochemical and chemical industries, is a labor-intensive production and it is accompanied by the formation of various wastes that have a negative impact on the environment. In order to involve alumina waste from polyeth-

\footnotetext{
* Corresponding Author.

Email: mi-shavkat@yandex.ru (S. Mamatkulov)
}

ylene production for the industrial and economic circulation, the possibility of complex processing of this technogenic raw material into the followings is proved: 1) fresh adsorbent Uz-AD-1 for purifying hydrogen from chlorine-containing impurities at a naphtha reforming unit was proved [1]; 2) a component of carriers of catalysts for hydrotreating, prehydrotreating and demetallization of heavy oil feedstock [2]; 3) pseudoboehmite for the synthesis of an adsorbent of 
a protective layer for the process of oxidative conversion of hydrogen sulfide [3]. The adsorbent Uz-AD-1, which was developed by us, as well as its imported counterparts, is inevitably turned into a waste category after 1-2 years of operation. The solution to the problem of processing these wastes, containing a large amount of chemisorbed corrosive substances, is very important for enterprises where installations provide a halogenation procedure during the regeneration of reforming catalysts. Due to the huge demand for high-quality gasoline, we know about the hardware design $[4,5]$ and the features of various naphtha reforming processes [6,7], the kinetics of reactions [8], causing an increase in the octane number of low-boiling hydrocarbons, the development and production of new catalysts [9-12] for implementation. The formation of acidic and metallic Pt centers, the mechanism of coke formation [13], the influence of a number of factors on the degree of deactivation of reforming catalysts [14], and optimization of the conditions for their regeneration [15] have been studied in detail. Information on the purposeful preparation of specific adsorbents for the auxiliary process of purification of hydrogen-containing gas from halogen-containing compounds is reflected mainly in patents [16-18], and insufficient attention has been paid to the disposal of spent adsorbents [19].

In this paper we presents the results of thermochemical activation of the Axstrap-860 adsorbent, spent in the process of purifying a hydrogen-containing reforming gas of the fuel direction with an emphasis on recycling and waste-free technology of its regeneration. The role of hydrogen in oil refining, petrochemistry and organic chemistry can hardly be overestimated. Hydrogen at oil refineries (refineries) is obtained in the process of catalytic reforming, in which it is formed as a by-product and it is used as a reagent in the hydrodesulfurization of fuels and oils after purification. However, reforming hydrogen does not fully meet the needs of even hydrogenation processes, not to mention the large tonnage production of ammonia. As a result, in the mid-70s, in the midst of the first wave of the energy crisis, hydrogen energy was developed vigorously and it is produced purposefully [20]. Interest in hydrogen has not faded away to this day [21,22]. Technical hydrogen with a purity of 97-97 \%vol, suitable for hydrotreating and hydrocracking, is produced by vapour conversion, either natural gas or straight-run gasolines [23]. Vapor conversion of methane is currently one of the basic processes in the chemical industry [24-26], so that inten- sive research is being carried out to develop efficient and reliable fuel processors - generators of synthesis gas and hydrogen into fuel for power plants [27-29]. In order to implement the principle of "multi-fuel", i.e., the conversion of various types of hydrocarbon raw materials into a mixture of $\mathrm{H}_{2}$ and $\mathrm{CO}$, Zyryanova et al. [29] selected NIAP-18, a catalyst for vapour and vapour-carbon dioxide conversion of natural gas. This is an industrial catalyst, tableted from a high-alumina carrier in the form of cylindrical rings, calcined at $1500{ }^{\circ} \mathrm{C}$. The main active component of the catalyst is an inserted nickel oxide with 3.7 wt.\% $\mathrm{Ca}$ and $0.5 \mathrm{wt} . \% \mathrm{Mg}$ promoters. At the same time, the authors emphasize the need for further improvement of the catalyst in order to increase its coke resistance.

Previously, the coke deposits on K-38 $\left(\mathrm{NiO} / \mathrm{MgAl}_{2} \mathrm{O}_{4}\right)$ catalyst were absent, both in a laboratory unit and after 10 months of its operation as a frontal layer in the process of steam conversion of heavy refinery gases at the Gas Plant of PA Angarsknefteorgsintez. Therefore, the possibility of synthesizing magnesiumaluminum spinel [30] was simultaneously considered as a useful by-product in demand of various industries [31-35] during the production of a new adsorbent of chlorine-containing compounds based on the spent adsorbent Axstrap-860, unloaded from the adsorber of the naphtha reforming unit of the Bukhara Refinery.

\section{Materials and Methods}

For the complex processing of secondary aluminum-containing raw materials, the following reagents were used: the Axstrap-860 adsorbent spent in the process of cleaning offgases from chlorine-containing compounds (Bukhara Refinery, Uzbekistan); $\mathrm{NaOH}, 25 \%$ $\mathrm{NH}_{4} \mathrm{OH}$ and $65 \% \quad \mathrm{HNO}_{3}$ (Navoiazot JSC, Uzbekistan); KOH (CHEMPACK, Russia), $\mathrm{MgO}$ (MAGNIKORM, Russia); $\mathrm{Ni}\left(\mathrm{NO}_{3}\right)_{2} 6 \mathrm{H}_{2} \mathrm{O}$ (OJSC Ural Plant of Chemical Reagents, Russia).

The content of the main elements (aluminum, sodium, and chlorine) in solid waste adsorbents was determined using a scanning electron microscope EVOMA 10 (Zeiss). The porous characteristics and specific surface of the carriers and catalysts were determined using a Carlo Erba porosimeter by mercury penetration under pressure from 0 to $200 \mathrm{MPa}$. The concentration of aluminum in solutions was determined by complexometric titration, chloride ions on argentometric 
titration, and sodium on flame photometry. The relative content of chlorinated oligomers in the sediments was estimated by the appearance of the $1270-1300 \mathrm{~cm}^{-1}$ band when recording IR spectra in the incomplete internal reflection mode on a Nicolet S50 spectrometer. Diffraction patterns of the samples were obtained on a diffractometer (Empyrean Diffractometer), and thermograms on a HESON HS-TGA-103 derivatograph within the temperature range of $298-1273 \mathrm{~K}$ with a heating rate of $10 \mathrm{~K} / \mathrm{min}$. Electronic spectra of diffuse reflectance of indicators which were adsorbed to identify the main centers on the surface of the studied adsorbents, were recorded on a Hitachi-330 spectrometer [36,37].

The ability of the obtained adsorbents to form chlorinated oligomers was assessed by the appearance of chlorhexane (band 850-650 in the IR spectrum) in the composition of gaseous reaction products formed by passing a gas mixture - hydrogen or dried nitrogen containing 7$8 \mathrm{~g} / \mathrm{m}^{3} \mathrm{HCl}, 10 \mathrm{~g} / \mathrm{m}^{3}$ hexane, and $2.5 \mathrm{~g} / \mathrm{m}^{3}$ hexene-1, through $15 \mathrm{~cm}^{3}$ of the adsorbent at a rate of $20 \mathrm{~L} / \mathrm{h}$ at $323-328 \mathrm{~K}$ for more than 200

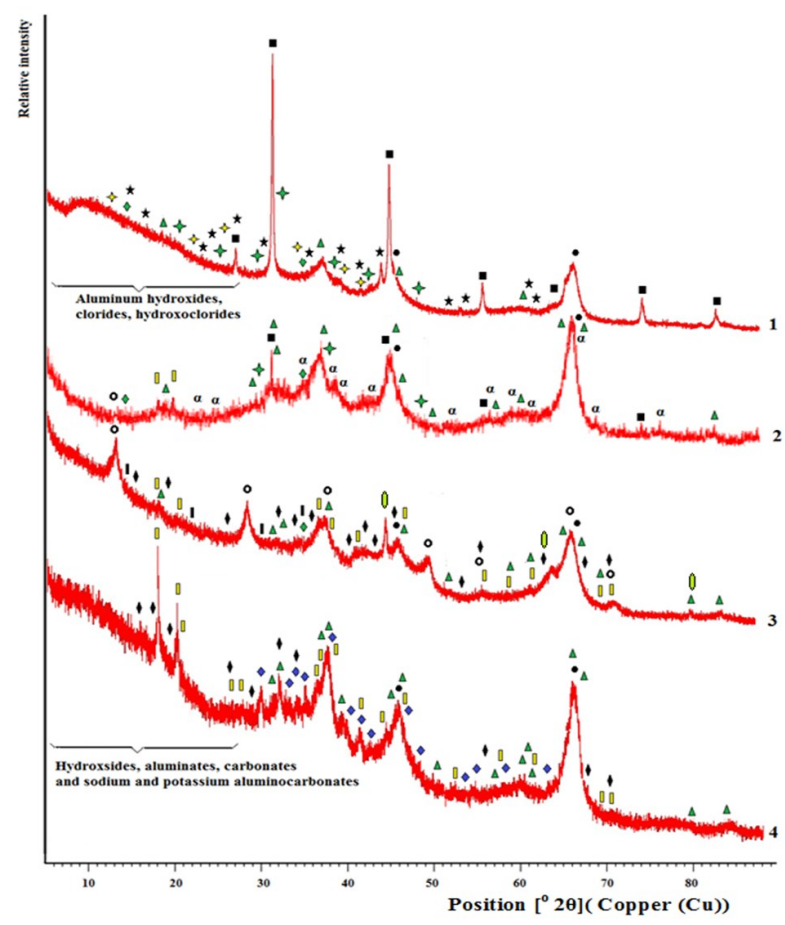

Figure 1. Diffraction patterns of samples at different stages of preparation of the modified adsorbent Uz-AD-6. (1)-spent Axstrap-860; (2)washed and dried Axstrap-860; (3) - fresh Axstrap-860; (4)-Uz-AD-6. $\bullet-\gamma-\mathrm{Al}_{2} \mathrm{O}_{3}, \Delta-\mathrm{Al}_{10.66} \mathrm{O}_{16}$, - $-\mathrm{NaCl}, \quad \mathbb{- a}-\mathrm{Al}(\mathrm{OH})_{3}, \quad \boldsymbol{0}-\mathrm{AlOOH}, \quad \boldsymbol{\alpha}-\alpha-\mathrm{Al}_{2} \mathrm{O}_{3}$, - $\mathrm{Na}_{2} \mathrm{CO}_{3},-\mathrm{NaAlCO}_{3}(\mathrm{OH})_{2}, \mathbf{I}-\mathrm{NaOH} \cdot \mathrm{H}_{2} \mathrm{O}$, 0 - $\mathrm{MgO}, \uparrow$-calcium chloride, $\diamond$-magnesium chloride. hours in a circulation mode. In addition, the changes in the IR spectrum of the adsorbents were considered before and after the passage of the specified model mixture in a cyclic mode.

The obtaining a new Uz-AD-6 adsorbent was carried out in several stages, taking into account the uneven distribution and chemical properties of adsorbed substances in the spent Axstrap-860. Hydrogen and hydrocarbons in the composition of the gas being purified were weakly bound to the adsorbent material (mainly physical adsorption) and were easily displaced from its surface by polar $\mathrm{HCl}$ and $\mathrm{H}_{2} \mathrm{O}$ molecules during the adsorption process. Chemisorption, i.e. adsorption with the formation of new chemical compounds proceeded while interacting with alkaline substances, and then with aluminum hydroxides in the composition of fresh Axstrap-860 (Figure 1, diffractogram 3 ) according to reactions 1-4:

$$
\begin{gathered}
\mathrm{NaOH} \cdot \mathrm{H}_{2} \mathrm{O}+\mathrm{HCl} \rightarrow \mathrm{NaCl}+2 \mathrm{H}_{2} \mathrm{O} \\
\mathrm{NaAlO}_{2}+4 \mathrm{HCl} \rightarrow \mathrm{NaCl}+2 \mathrm{H}_{2} \mathrm{O}+\mathrm{AlCl}_{3} \\
\mathrm{NaAlCO}_{3}(\mathrm{OH})_{2}+4 \mathrm{HCl} \rightarrow \mathrm{AlCl}_{3}+\mathrm{NaCl} \\
+\mathrm{CO}_{2}+3 \mathrm{H}_{2} \mathrm{O} \\
\mathrm{AlOOH}+3 \mathrm{HCl} \rightarrow \mathrm{AlCl}_{3}+2 \mathrm{H}_{2} \mathrm{O}
\end{gathered}
$$

The maximum concentration of sodium and aluminum chlorides was observed in the frontal layer of an industrial adsorber and gradually decreased until there was no $\mathrm{AlCl}_{3}$ at the outlet. Chlorides and hydroxochlorides of aluminum were formed during the interaction of boehmite in the composition of a fresh adsorbent with $\mathrm{HCl}$, and $\mathrm{NaCl}$ with surface $\mathrm{X}$ ray amorphous sodium aluminates (Figure 1). The contact of the spent Axstrap-860 with water was accompanied by partial (15-20 \%mass) destruction of granules up to a powdery statedue to their hygroscopicity. Therefore, the spent adsorbent was first washed with water, the whole granules were separated on a sieve, they were dried and calcined at $700-710 \mathrm{~K}$ to remove $\mathrm{AlCl}_{3}$ residues and coke-like deposits [1] (Table 1). Then the calcined granules were impregnated with an alkaline solution containing $195 \mathrm{~g} / \mathrm{L} \mathrm{NaOH}$ and $45 \mathrm{~g} / \mathrm{L} \mathrm{KOH}$, taking into account the moisture absorption of 47-55 \%mass, they were dried in air and put in a muffle furnace at a temperature not higher than $570 \mathrm{~K}$. After settling the wash water suspension, a clear solution containing $\mathrm{NaCl}$, chlorides and aluminum hydroxochlorides was separated by decantation. Then this solution was sent to separate the corresponding salts as useful byproducts - sodium and aluminum chlorides. Meanwhile, the sediment consisting of fine 


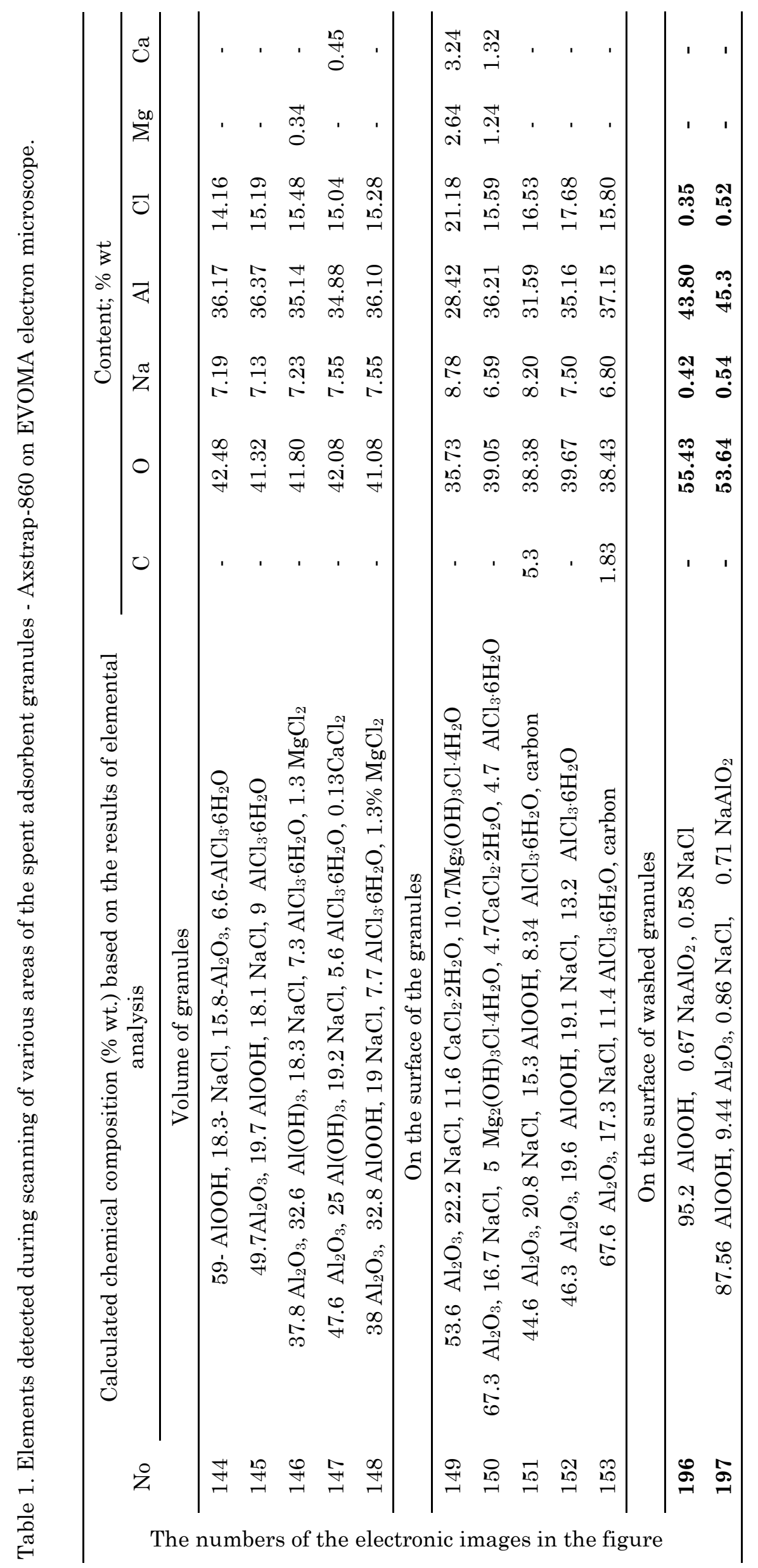


particles of $\gamma-\mathrm{Al}_{2} \mathrm{O}_{3}$ and $\mathrm{Al}(\mathrm{OH})_{3}$ in a mixture with crumbs of destroyed granules, and containing no more than $3 \% \mathrm{Cl}^{-}$mass, served as a raw material for obtaining pseudoboehmite. For this purpose, the sediment was dissolved in nitric acid with a density of $1.26-1.27 \mathrm{~g} / \mathrm{mL}$ at a temperature of $360-365$ $K$. Then the aluminum nitrate solution was decanted into a vessel equipped with a stirrer after cooling.

The deposition of aluminum monohydroxide was carried out with a $25 \%$ mass. $\mathrm{NH}_{4} \mathrm{OH}$ solution maintaining $\mathrm{pH}$ of 7-7.5. The maturation of sediments, subsequent filtration and washing on a nutsch filter was carried out at a temperature of 290-295 K, and drying to a powdery state at $360 \mathrm{~K}$. The $\gamma-\mathrm{Al}_{2} \mathrm{O}_{3}$ adsorbent was obtained by molding dried pseudoboehmite followed by calcining at $825 \mathrm{~K}$ and this absorbent was intended for removing droplet moisture from wet process gases. Aluminum monohydroxide powder in the form of a gel-like pseudoboehmite with a crystal size of 20-30 , was thoroughly mixed with magnesium oxide and water in an atomic ratio of $\mathrm{Mg}: \mathrm{Al}=1: 2$ for 4-5 hours for destructive-epitaxial interaction in order to obtain a bidispersed magnesiumaluminum spinel. As a result of the partial dissolution of poorly soluble reagents in water, there was a gradual formation of magnesium hydroxoaluminates witha pseudoboehmite morphology [38]. Then the mass was mixed again, evaporated to a consistency suitable for molding by extrusion into Raschig rings with a diameter of $15 \times 2 \mathrm{~mm}$. Having dried in air, the pellets were heated by raising the temperature in a muffle furnace at a rate of $20-30 \mathrm{~K} / \mathrm{h}$ up to
1440-1450 K with holding at this temperature for 5 hours.

The $\mathrm{NiO} / \mathrm{MgAl}_{2} \mathrm{O}_{4}$ catalyst was prepared by moisture absorption impregnation of magnesium-aluminum spinel granules with a $58 \%$ aqueous solution of $\mathrm{Ni}\left(\mathrm{NO}_{3}\right)_{2} \cdot 6 \mathrm{H}_{2} \mathrm{O}$, the catalyst after calcination at $873 \mathrm{~K}$ contained 12 \%mass. $\mathrm{NiO}\left(0.26 \mathrm{M} \mathrm{NiO} / 1 \mathrm{M} \mathrm{MgAl}_{2} \mathrm{O}_{4}\right)$. The acid reference catalyst obtained similarly by impregnation of $\gamma-\mathrm{Al}_{2} \mathrm{O}_{3}$ from fresh pseudoboehmite contained $0.19 \mathrm{M} \mathrm{NiO} / 1 \mathrm{M} \gamma-\mathrm{Al}_{2} \mathrm{O}_{3}$. The activity of the catalysts was evaluated in a laboratory setup by the degree of hexane conversion in a model mixture of hexane and water vapors $\left(\mathrm{H}_{2} \mathrm{O}: \mathrm{C}=3: 1 \mathrm{~mol} / \mathrm{g}\right.$-atom $)$ in a helium flow, and the selectivity by the amount of coke deposits. The process was carried out at a temperature of $773 \mathrm{~K}$, at a pressure of 0.1 $\mathrm{MPa}$, a space velocity of $4 \mathrm{~h}^{-1}$ for liquid hydrocarbon, and a hexane:helium ratio of 1:40. The composition of the model mixture and gaseous reaction products, as well as the chemisorption of hydrogen during the temperatureprogrammed reduction of the samples, was determined on a Chrom 5 chromatograph.

\section{Results and discussion}

In the process of optimizing the preparation conditions for Uz-AD-6 from the spent adsorbent Axstrap-860 (specific surface area $70-177 \mathrm{~m}^{2} / \mathrm{g}$ ), the necessary and sufficient degree of removal of chlorine ions was revealed: from 5-20 \%mass, $\mathrm{Cl}$ up to 1-2 \%mass, and residual chlorine after completion of the water treatment and calcination procedure. More than half of the chemisorbed substances remain in the test sample with a
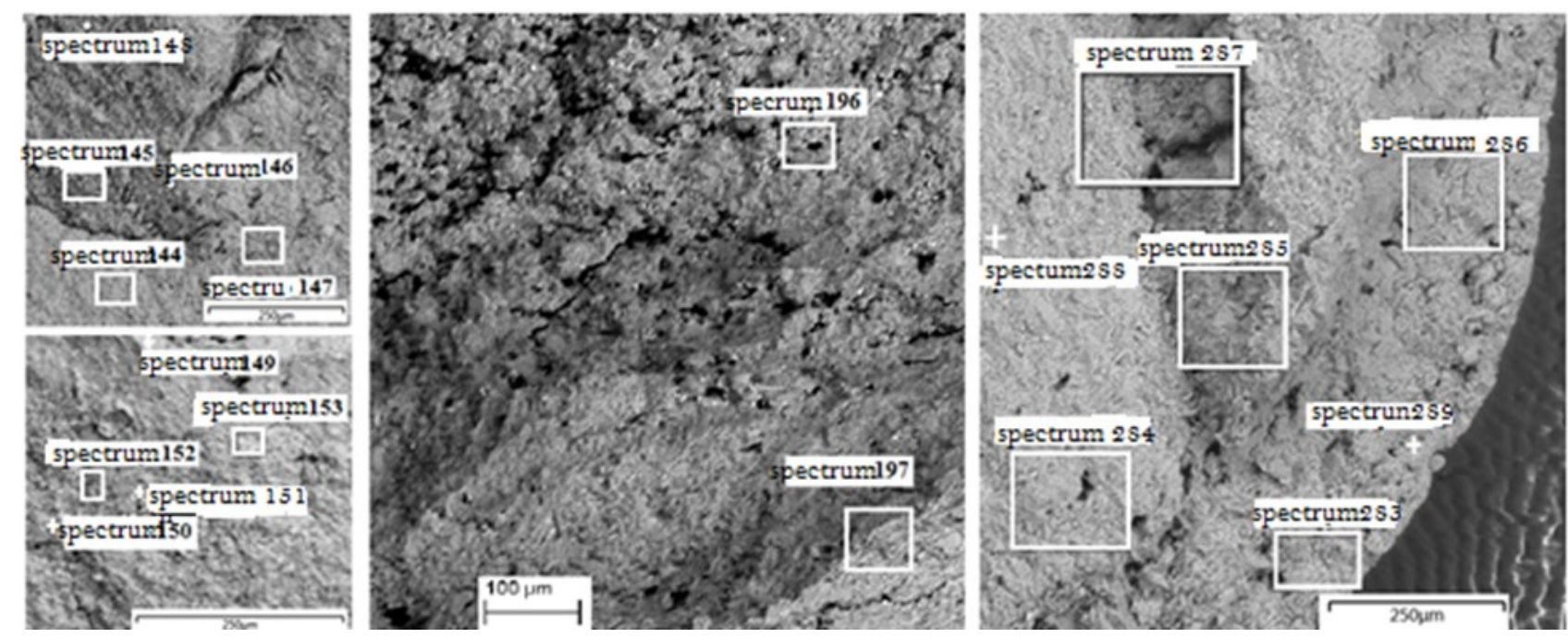

Figure 2. Photo of a cut of the spent adsorbent granules: on the left (top - the middle of the granule, below - the surface layer), the granule after washing with water and calcining in the center, and on the right - finished Uz-Ad-6. 
washing time of less than 10 hours. However, treatment with water for more than 24 hours is accompanied by the formation of an excessive amount of a low-concentrated suspension that is not suitable for further processing. The concentration of residual chlorine identified after calcining the washed granules in the temperature range of $670-570 \mathrm{~K}$ was below 0.5 $\%$ mass, and the specific surface area reached $280-300 \mathrm{~m}^{2} / \mathrm{g}$ due to the sublimation of aluminum chloride and burnout of carbon deposits [1] (Table 1). A feature of the morphology of the studied samples is the formation of a relatively loose layer with a thickness of about $250 \mu \mathrm{m}$ and a denser middle part (Figure 2, photo on the right).

This phenomenon is explained by the expansion of pores and microcracks due to the extraction of the products of the interaction of chlorine-containing compounds from them with X-ray amorphous sodium aluminates and boehmite in the composition of the adsorbent. A powerful halo in the range of small angles $2 \theta=$ $7.6^{\circ}-7.82^{\circ}(d=11.6-11.3 \AA)$ witnesses the presence of surface sodium aluminates in fresh Axstrap-860. There are lines of $100 \%$ intensity of the phases $\mathrm{NaAl}_{11} \mathrm{O}_{17}, \mathrm{NaAl}_{7} \mathrm{O}_{11}, \mathrm{NaAl}_{5} \mathrm{O}_{8}$ and $\mathrm{NaAl}_{3} \mathrm{O}_{6}$ (Figure 1, diffractogram 3). Weaker halos in the range of $2 \theta=15.5^{\circ}-16.6^{\circ}$, $19.6^{\circ}-26.8^{\circ}, \quad 31.0^{\circ}-35.8^{\circ}, \quad 40.5^{\circ}-45.9^{\circ}, \quad 57.9^{\circ}-$ $63.0^{\circ}$ and $66.0^{\circ}-68.8^{\circ}(d=5.69-5.30,4.5-3.3$, $2.88-2.5,1.588-1.47$ and $1.41-1.36 \AA$ A) located between the intense lines of boehmite and they can be attributed to the manifestation of not only sodium polyaluminates, but also $\mathrm{NaAlO}_{2}$ and $2 \mathrm{NaAlO}_{2} \cdot 3 \mathrm{H}_{2} \mathrm{O}$.

The solid crust covering the pore walls of the spent Axstrap-860 (Figure 2, bottom left photo; Table 1) consists of coarse crystalline $\mathrm{NaCl}(d=$ $3.32,2.88,2.033,1.66,1.44,1.284$ and $1.17 \AA$ A) and sometimes anhydrous $\mathrm{AlCl}_{3}$, weakly crystallized $\mathrm{AlCl}_{3} \cdot 6 \mathrm{H}_{2} \mathrm{O}$ (broad lines with $d=$ $6.0,5.2,3.89,3.69,3.29,2.57,2.3$, and $2.05 \AA$ ). An intense halo in the range of $2 \theta=7.7-28^{\circ}$ (Figure 1, diffractogram 1) indicates the presence of a mixture of several hydrolyzed forms of polynuclear hydroxo complexes of variable composition, which are expressed by the general formula $\left[\mathrm{Al}(\mathrm{OH})_{3-\mathrm{x}} \mathrm{Cl}_{\mathrm{y}}\right]_{\mathrm{n}}$, where $\mathrm{x}$ varies within $0-3$ [1].

In the diffraction patterns of the heavily hardened Axstrap-860 (frontal layer), the $\mathrm{AlCl}_{3}$ $6 \mathrm{H}_{2} \mathrm{O}$ and $\mathrm{AlCl}_{3}$ lines appear very well, as well as in the one stripped off and dried aqueous extract both before and after separation of $\mathrm{NaCl}$ crystals. When heated to a temperature of 455 $\mathrm{K}$, the spent Axstrap-860, especially the dried aqueous extract, $\mathrm{AlCl}_{3}$ sublimates. According to the results of elemental analysis, the composition of the dry extract on average corresponds to the formula $\mathrm{Al}_{2}(\mathrm{OH})_{5.2-5.0} \mathrm{Cl}_{1.0-0.8}$, i.e. it is close to the composition to aluminum pentahydroxochloride - a coagulant with the maximum coagulating ability among other aluminum hydroxochlorides.

We can assume the presence of magnesium and calcium chlorides based on the results of computer processing of diffraction pattern 1 in Figure 1: $\mathrm{CaCl}_{2}-d=4.49,3.46,3.05,2.85,2.33$, $2.24,2.09,1.9,1.79,1.68 \AA, \mathrm{CaCl}_{2} 6 \mathrm{H}_{2} \mathrm{O}-d=6.9$ $12.8,3.93,3.41,2.78,2.58,2.27,2.16 \AA \mathrm{AgCl}_{2}-$ $d=5.9,2.94,2,55,1.80 \AA, \mathrm{MgCl}_{2} \cdot 6 \mathrm{H}_{2} \mathrm{O}-d=$ $5.8,4.10 \AA$. Indications of the presence of magnesium and calcium compounds are also found in the diffractograms of fresh Axstrap860 (Figure 1, diffractogram 3).

Complexometric titration with a solution of the sodium salt of ethylenediaminetetraacetic acid, first at $\mathrm{pH} 12-13$ in the presence of murexide as an indicator, confirmed the presence of $\mathrm{Ca}^{2+}$ cations, and then at $\mathrm{pH}=10 \mathrm{Mg}^{2+}$ in the composition of fresh and used Axstrap-860. The presence of inclusions of calcium and magnesium compounds in some samples was also recorded on a scanning electron microscope (Figure 2, Table 1). In the Axstrap-860 used, the content of $\mathrm{Na}$ and $\mathrm{Cl}$ in the surface layer of the granules was in the range of 4.3-5.4 and $8.5-9.3 \%$ of the mass, respectively, and in the middle of the granules is slightly less: 2.9-3.3 and $1.2-1.5 \%$ of the mass.

In the process of alkaline modification, due to the presence of transport channels with a width of about $12 \mu \mathrm{m}$, which are clearly visible on the cut of the granule (Figure 2, photo in the center), the joint solution of sodium and potassium hydroxides freely penetrated deep into the granules, purified from the bulk of substances $\left(\mathrm{NaCl}, \mathrm{AlCl}_{3} \times \mathrm{xH}_{2} \mathrm{O}\right.$ and $\left.\left[\mathrm{Al}(\mathrm{OH})_{3-\mathrm{x}} \mathrm{Cl}_{\mathrm{y}}\right]_{\mathrm{n}}\right)$, which blocked the pores of the spent adsorbent. The specificity of the obtained adsorbent is the almost complete absence of the phase of aluminum monohydroxide, which is replaced by aluminum trihydroxide - gibbsite. When statistically processing the results of elemental analysis of a series of Uz-AD-6 samples, the concentration in the outer layer of granules was within 6.5-9.2 Na\% and 1-5 K\%, and in the inner volume, respectively, 2.5-3.5 Na\% and 0.5-0.7 $1.5 \mathrm{~K} \%$ (Table 2). Based on the molar ratio of carbonate carbon and alkali metals in the composition of representative samples (10 g each), it was concluded that the amorphous phase of sodium aluminate $\mathrm{Na}_{7} \mathrm{Al}_{3} \mathrm{O}_{8}$ prevails over sodium and potassium monoaluminates. The finished Uz-AD-6 contains water-soluble sodium 


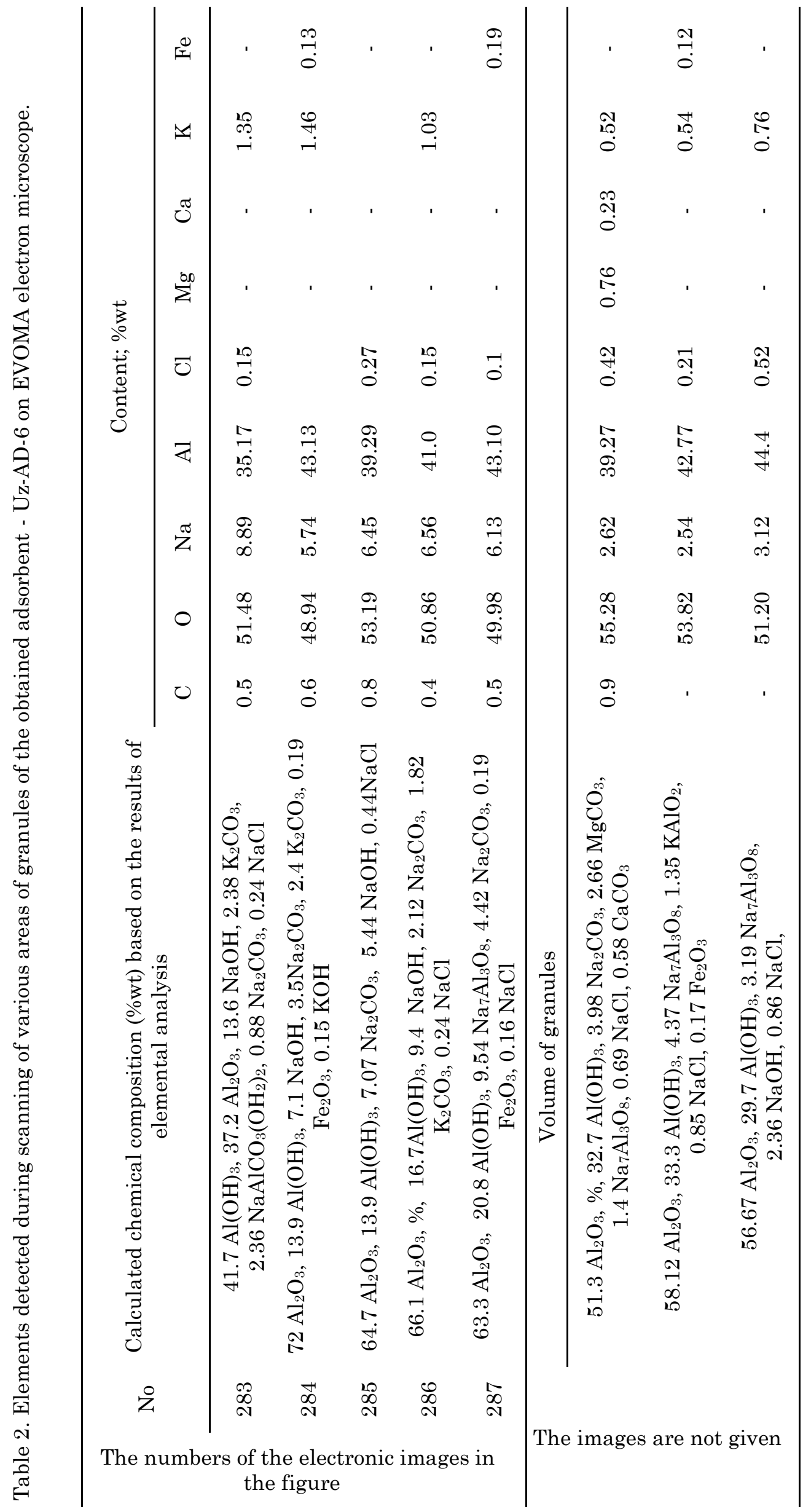


and/or potassium carbonates, in contrast to $\mathrm{NaAlCO}_{3}(\mathrm{OH})_{2}$ identified in fresh Axstrap-860. The presence of insoluble sodium carboaluminate $\mathrm{NaAlCO}_{3}(\mathrm{OH})_{2}$ was confirmed by the reaction of $\mathrm{CO}_{2}$ release upon addition of hydrochloric acid solution to the adsorbent sample after preliminary removal of soluble sodium carbonates by aqueous extraction. Carbonate carbon in the composition of sodium, calcium and magnesium carbonates and/or carboaluminates was estimated by the amount of $\mathrm{CO}_{2}$ released during the interaction of a sample of the adsorbent composition with hydrochloric acid.

In addition to $0-0.3 \%$ mass. residual chlorine, when viewed through an electron microscope, point inclusions of corrosive iron are observed, which cannot be removed by water and heat treatment. Calcium and magnesium recorded in some areas indicate incomplete removal of chlorides at the washing stage and / or the introduction of hardness salts with tap water.

In general, during the complex processing of $50 \mathrm{~kg}$ of spent Axstrap-860, 34.2 $\mathrm{kg}$ of a new Uz-AD-6 adsorbent were obtained, $2.4 \mathrm{~kg}$ of crystalline $\mathrm{NaCl}$ and $13.5 \mathrm{~kg}$ of dried aluminum

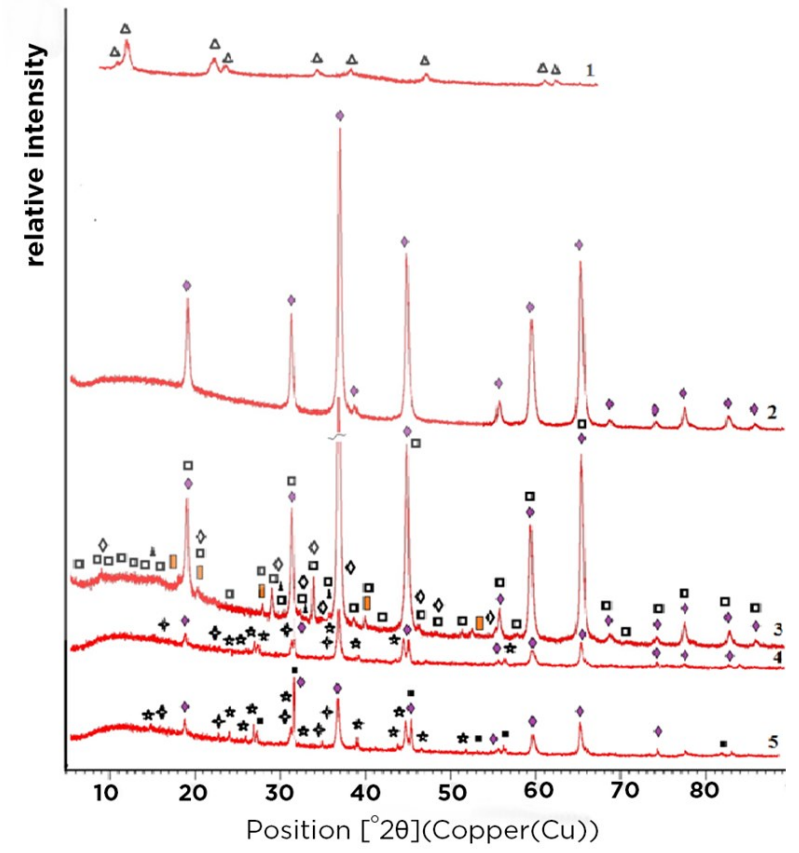

Figure 3. Diffraction patterns of (1) magnesium hydroxoaluminate, (2) $\mathrm{MgAl}_{2} \mathrm{O}_{4}, \quad$, (3) $\mathrm{MgAl}_{2} \mathrm{O}_{4} \mathrm{NaOH}$; after exposure to saturated vapors of a mixture of hydrochloric acid, tetrachlorethylene and hexene- 1 of the samples: (4) $\mathrm{MgAl}_{2} \mathrm{O}_{4}$, (5) $\mathrm{MgAl}_{2} \mathrm{O}_{4}-\mathrm{NaOH}$. $-\mathrm{MgAl}_{2} \mathrm{O}_{4}$, $\boldsymbol{\Delta}$-magnesium hydroxoaluminates, $\mathbf{0}$-magnesium carbonates, $\boldsymbol{\nabla}$-sodium carbonates, [-bayerite, \$-magnesium chlorides, * -chlorides aluminum, - -sodium chloride, l-sodium hydroxide. hydroxychloride were isolated from the wash water, and $6.8 \mathrm{~kg}$ of aluminum hydroxide of pseudoboehmite modification was obtained from the insoluble residue of the suspension by reprecipitation. Our attempt to use aluminum hydroxide obtained as a by-product in the production of the Uz-AD-6 adsorbent for the synthesis of magnesium-aluminum spinel showed that freshly precipitated pseudoboehmite AlOOH stabilized by residual $\mathrm{NH}_{4}{ }^{+}, \mathrm{NO}_{3}{ }^{-}$ions and nitrohydroxocomplexes readily undergoes destructive epitaxial transformations $\mathrm{AlOOH}$ $\mathrm{MgO}-\mathrm{H}_{2} \mathrm{O}$.

In the IR spectra of the dried mass intended for the formation of Raschig rings, an intense band at $1390 \mathrm{~cm}^{-1}$, corresponding to nitrate ions, remains, along with the appearance of a series of bands indicating the formation of magnesium hydroxoaluminates: a narrow band at $420 \mathrm{~cm}^{-1}$ and a wide band with maxima at 480 and $580 \mathrm{~cm}^{-1}$. That is, partial dissolution of $\mathrm{MgO}$ with the formation of $\mathrm{Mg}^{2+}$ and $\mathrm{OH}^{-}$ions, their subsequent adsorption on the surface of loose particles of less soluble $\mathrm{AlOOH}$ with a gradual rearrangement of its crystal lattice up to complete transformation into magnesium hydroxoaluminate. This follows from the disappearance in the diffractogram of the resulting paste (Figure 3, diffractogram 1) of broad lines characteristic of weakly crystallized pseudoboehmite $(d=6.10,3.16,2.34,1.86,1.85$, $1.66 \AA$ A) and narrower lines from the initial magnesium oxide $(d=2.43,2.09$, and 1.35$)$, instead of which a set of lines with $(d=8.03$, $7.61,4,05,4.01,3.82,2.614,1.97,1.515$, and $1.493 \AA$ A) belonging to magnesium hydroxoaluminates is observed. Due to the epitaxial growth of new formations, the crystals of the newly formed phase have dimensions of the same order of magnitude as the $\mathrm{AlOOH}$ crystals. Upon completion of the reactions in the $\mathrm{AlOOH}-\mathrm{MgO}-\mathrm{H}_{2} \mathrm{O}$ system, a paste is formed from partially intergrown crystals of magnesium hydroxyaluminates. After calcination, due to the removal of gaseous products, the size of the $\mathrm{MgAl}_{2} \mathrm{O}_{4}$ crystals becomes smaller, but their configuration is retained during dehydration. The morphological feature of the obtained spinel is the formation of grape-like particles with $1 \mu \mathrm{m}$ sizes, which determine its biporous structure and maintain high mechanical strength upon repeated heating to $1000 \mathrm{~K}$ and rapid cooling. A thermographic study revealed a complete disappearance of the exothermic effect at $543 \mathrm{~K}$ observed on the DTA curve of the synthesized pseudobemite due to the thermal decomposition of the incompletely washed ammonium nitrate. In addition, a shift of the 
stretched endothermic effect around $665 \mathrm{~K}$ was observed, characteristic of $\mathrm{AlOOH}$ dehydration with transition into $\gamma-\mathrm{Al}_{2} \mathrm{O}_{3}$ to the lowtemperature region, as well as the endothermic effect from the transformation of $\mathrm{Mg}(\mathrm{OH})_{2}$ into $\mathrm{MgO}$ at $855 \mathrm{~K}$. Instead the following are observed: a deep endo-effect at 400-408 K, and less intense endothermic effects at 620 and 795 $\mathrm{K}$ accompanied by mass loss of 37,20 , and $4 \%$, respectively. According to the TH curve, the dehydration processes of magnesium hydroxoaluminates end around $870 \mathrm{~K}$ with the formation of X-ray amorphous products. At the further rise in temperature up to $1440-1450 \mathrm{~K}$ the degree of crystallinity increases and sintering of $\mathrm{MgAl}_{2} \mathrm{O}_{4}$ crystals begins. But as in the case of industrial pseudobemite [30], spinel particles obtained through destructive-epitaxial transformations present open-worked formations, resulting in high strength - $380-390 \mathrm{~kg} / \mathrm{cm}^{2}$, biporous structure and specific surface area of 28 $32 \mathrm{~m}^{2} / \mathrm{g}$. After calcination at $1450 \mathrm{~K}$, the volume of micropores measuring 30-100 А was $0.16 \mathrm{~cm}^{3} / \mathrm{g}$, and the volume of macropores measuring $1000-30000 \AA$ was $0.26 \mathrm{~cm}^{3} / \mathrm{g}$.

In the diffractogram of the calcined sample, in contrast to the magnesium-aluminum spinel prepared by the same technology, but from industrial aluminum hydroxides with crystal sizes 50-75 ̊ [30], only magnesium aluminate was identified. The crystal phase $\mathrm{MgAl}_{2} \mathrm{O}_{4}$ corresponded to lines with $d=4.657,2.858,2.453$, $2.31,2.008,1.637,1.55,1.424,1.3606,1.27$, $1.225,1.162$ and $1.1271 \AA$. The most intensive lines with $d=3.48,2.55,2.08,1.74$ and $1.61 \AA$, typical for $\mathrm{a}-\mathrm{Al}_{2} \mathrm{O}_{3}$ and with $d=2.10,1.485$ and $1.266 \AA$, corresponding to $\mathrm{MgO}$, were absent (Figure 3, diffractogram 2). Acidic centers with
pKa $\leq+3.8$ provoking coking were not identified on the spinel surface, the main centers with $\mathrm{pKa}$ about 9.3 prevailed, and also stronger main centers with $\mathrm{pKa}>+10.3$ were found.

The $\mathrm{NiO} / \mathrm{MgAl}_{2} \mathrm{O}_{4}$ catalyst, similarly to the K-38 catalyst, contained nickel mainly in the form of a nonstoichiometric oxide $-\mathrm{NiO}_{1+\mathrm{x}}$, which is capable of chemisorbing hydrogen at a temperature of $710-860 \mathrm{~K}$ with the formation of $\mathrm{Ni}^{\circ}$ - centers, which largely determine the selectivity of the steam conversion of hydrocarbons. $\mathrm{MgAl}_{2} \mathrm{O}_{4}$ and all adsorbents studied in the article did not chemisorb the hydrogen under conditions of temperature-programmed reduction within the temperature range of 295$970 \mathrm{~K}$, only physical adsorption was observed.

According to the results of testing the synthesized $\mathrm{NiO} / \mathrm{MgAl}_{2} \mathrm{O}_{4}$ catalyst under severe conditions similar to the testing of K-38 catalyst, which allow predicting catalytic properties, it was shown that the degree of hexane conversion \% with the formation of gaseous products $\left(\mathrm{H}_{2}, \mathrm{CO}, \mathrm{CO}_{2}, \mathrm{CH}_{4}\right)$ was at least $90 \%$ mass. in the model process of steam conversion of liquid hydrocarbons. Analysis of carbonaceous deposits revealed that the coke did not exceed $0.05 \%$ mass, while the amount of coke reached $0.35 \%$ mass on the $\mathrm{NiO} / \gamma-\mathrm{Al}_{2} \mathrm{O}_{3}$ catalyst of "acidic" nature.

Besides, in order to reveal possibility of application of magnesium-aluminum spinel as a protective (distributive) layer in adsorbers for gas purification from halide compounds in the presence of a lot of water vapor its modification by moisture absorption by $24 \%$ sodium hydroxide solution was carried out. From some displacement of $\mathrm{MgAl}_{2} \mathrm{O}_{4}$ lines in the diffractogram in Figure 3 we made an assumption
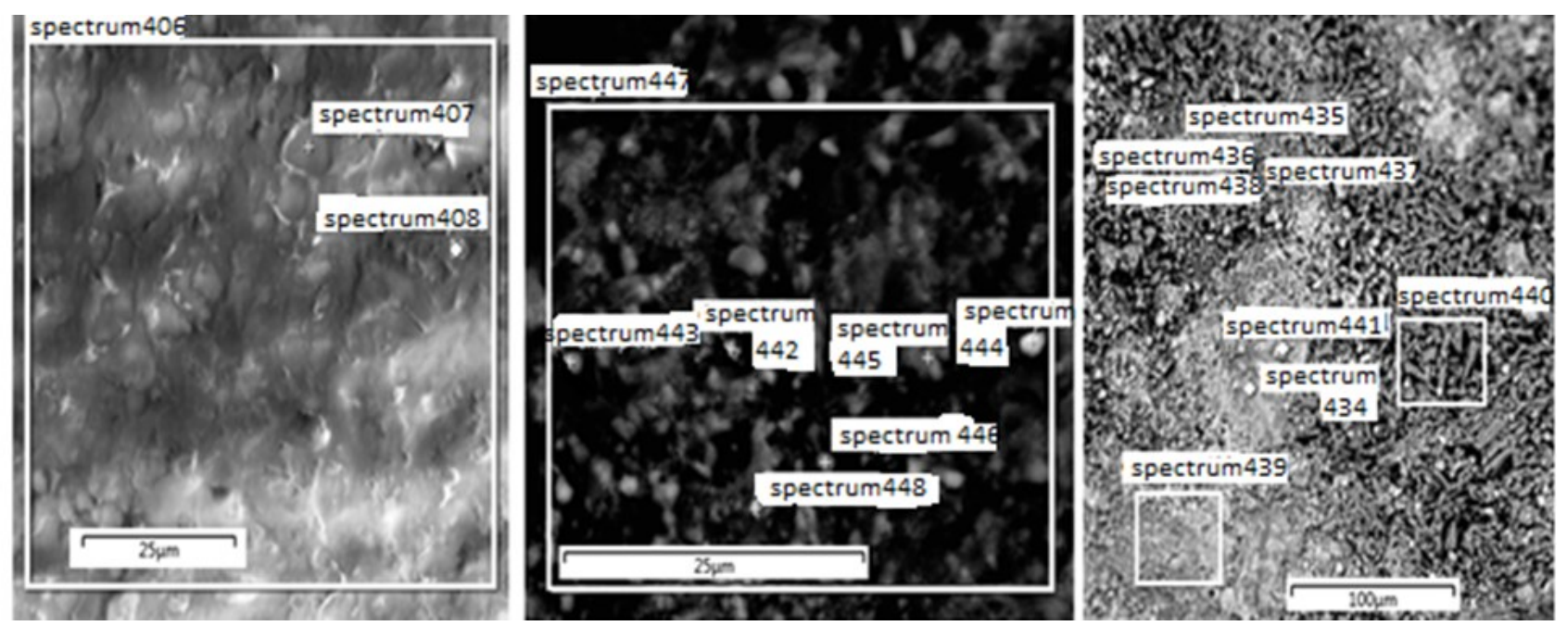

Figure 4. Photo of the surface of the original $\mathrm{MgAl}_{2} \mathrm{O}_{4}$ pellet (left); modified with sodium hydroxide (center and right side). 


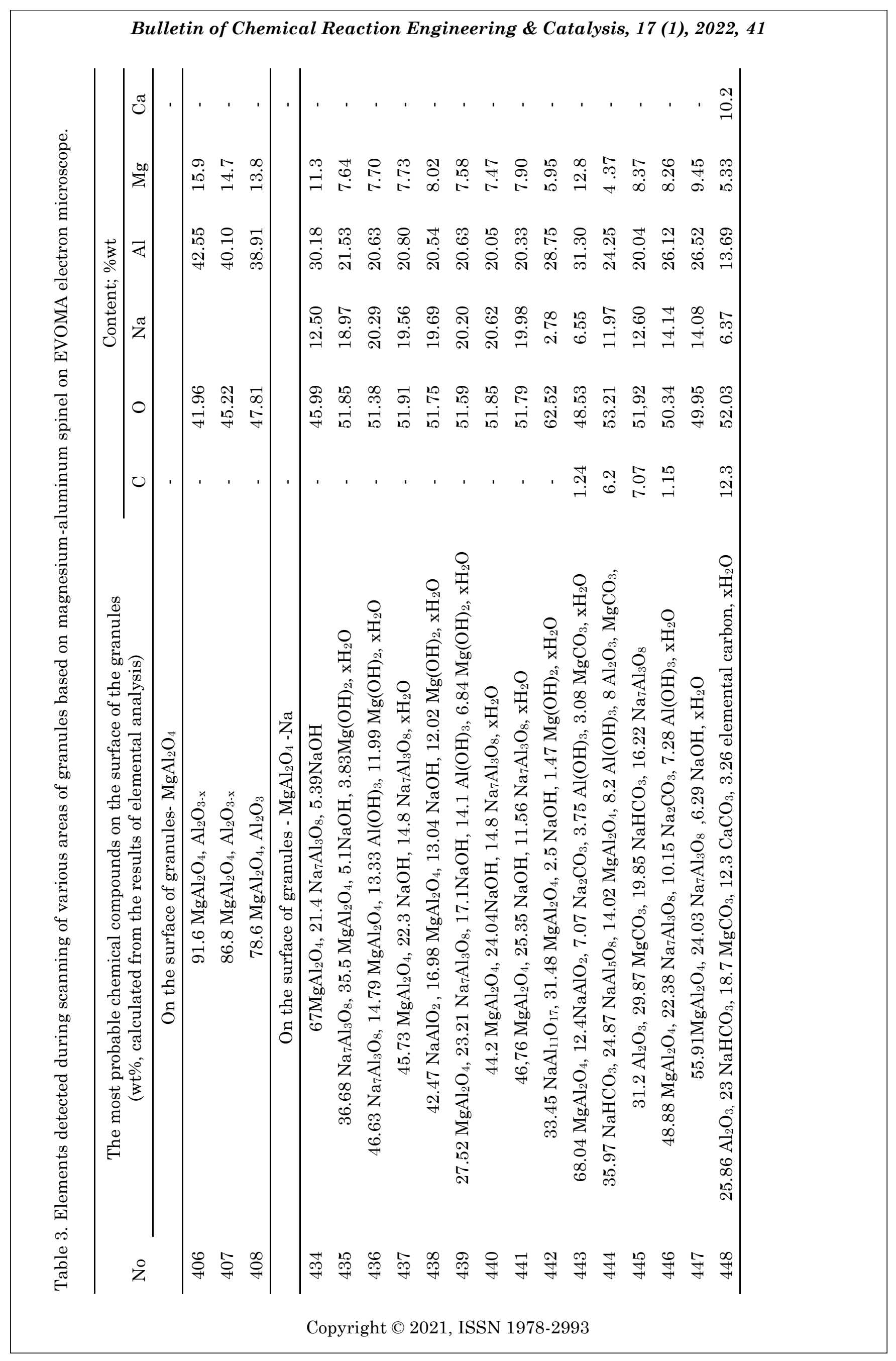


about the introduction of $\mathrm{Na}^{+}$ions into the crystal lattice of the magnesium-aluminum spinel. Appearance of separate distinct lines with $d=$ $3.18,3.053,2.75,2.64,2.31,2.2475,1.954$, $1.861,1.766,1.7288,1.632,1.586 \AA$ from crystalline phases that can be assigned to carbonates: $\mathrm{Na}_{2} \mathrm{CO}_{3}, \mathrm{Na}_{2} \mathrm{CO}_{3} .7 \mathrm{H}_{2} \mathrm{O}, \mathrm{MgCO}_{3} 2 \mathrm{H}_{2} \mathrm{O}$, $\mathrm{Mg}_{2}(\mathrm{OH})_{2} \mathrm{CO}_{3} .3 \mathrm{H}_{2} \mathrm{O}$, and $\mathrm{Mg}_{5}\left(\mathrm{CO}_{3}\right)_{4}(\mathrm{OH})_{2} .5 \mathrm{H}_{2} \mathrm{O}$ and halo in the low angle region with $2 \theta$ from 5.8 to $18^{\circ}$, corresponding to the most intense lines of magnesium carbonates, also indicates the migration of $\mathrm{Mg}^{2+}$ ions into the liquid phase during modification with subsequent interaction with atmospheric $\mathrm{CO}_{2}$. The above was confirmed by elemental analysis (Figure 4, Table 3) by the appearance of carbon in the composition of some sections of $\mathrm{MgAl}_{2} \mathrm{O}_{4}$ modified with sodium hydroxide. Fluctuations in the amount of carbon in the composition of the studied samples, not correlated with the content of alkali and alkaline earth metals, can be explained by the variation in the amount of compounds formed and their uneven macro-distribution.

Testing the type of surface centers revealed that $48 \%$ of pellets taken at random during adsorption from benzene solution ionized phenolphthalein molecule and acquired bright crimson color, $37 \%$ were colored in a slightly pink color ( $\mathrm{pKa}>+9.3)$, and the rest remained white. In accordance with the study [36] about half of the alkali metal hydroxides in the process of modification turned into a highly basic aluminate $-\mathrm{Na}_{7} \mathrm{Al}_{3} \mathrm{O}_{8}(\mathrm{pKa}>+9.3)$. From them one third of granules, as well as their separate sites (Figure 4, spectra No 435-441), containing an admixture of unreacted $\mathrm{NaOH}$ were capable to ionize thymolphthalein molecule, getting blue color characteristic for the main form of this indicator $(\mathrm{pKa}>+10.3)$. Appearance of slightly pink coloring of the main form of adsorbed phenolphthalein indicated formation of crystalline $\mathrm{Na}_{2} \mathrm{CO}_{3} .2 .5 \mathrm{H}_{2} \mathrm{O}$ (Figure 3, diffractogram 3, Figure 4 spectra No 443-446, 448.) in addition to other sodium and potassium carbonates and monoaluminates with main centers of moderate strength $(\mathrm{pKa} \approx 8.3-9.3)$. White coloration of granules after adsorption of phenolphthalein ( $\mathrm{pKa} \geq+8.3$ ), indicated the formation of sodium polyaluminates with low mass ratio $\mathrm{Na}: \mathrm{Al}$, namely $\mathrm{NaAl}_{11} \mathrm{O}_{17}, \mathrm{NaAl}_{7} \mathrm{O}_{11}$ and $\mathrm{NaAl}_{5} \mathrm{O}_{8}$ (Figure 4 spectra No 434, 442, 447). The results of studies of adsorption properties of samples based on the used adsorbent Axstrap-860 and a by-product of its processing are shown in Table 4, which shows that the new adsorbent obtained by processing the used adsorbent in its adsorption characteristics is close to the fresh Axstrap-860, designed for gas purification from halide compounds.

Under identical experimental conditions, adsorbents modified with alkali metal hydroxides did not catalyze the formation of chlorinated hydrocarbons. In the IR spectrum of these samples, after the completion of the experiment, an increase in the intensity of broad bands in the range of 3325-3000, 1643-1585, and $527-493 \mathrm{~cm}^{-1}$, characteristic for the initial adsorbents, was observed, and it is indicated the presence of adsorbed hydrocarbons, including hexene along with the appearance of a series of new inflection points at 1175-1205, 1055-1060, 980-960, 910-915, and 660-72 $\mathrm{cm}^{-1}$.

In contrast to them, already at the initial stage, on the $\gamma-\mathrm{Al}_{2} \mathrm{O}_{3}$ and $\mathrm{MgAl}_{2} \mathrm{O}_{4}$ adsorbents, the chemisorption of $\mathrm{HCl}$ was accompanied by a chemical reaction with aluminum oxide and by the formation of a strong Lewis acid $-\mathrm{AlCl}_{3}$.

Table 4. Dynamic adsorption capacity (g of adsorbate $/ 100 \mathrm{~g}$ adsorbent) recorded after flowing through $10 \mathrm{~cm}^{3}$ of adsorbent a mixture of nitrogen and model substances at a rate of $20 \mathrm{~L} / \mathrm{h}$ at $300 \mathrm{~K}$.

\begin{tabular}{lccccc}
\hline \multirow{2}{*}{ Sample } & $\begin{array}{c}\text { Capacity of } \\
\text { chloride* }\end{array}$ & & \multicolumn{3}{c}{$\begin{array}{c}\text { Absorbate capacity before a } \\
\text { "breakthrough"; g/100 g }\end{array}$} \\
\cline { 2 - 3 } \cline { 5 - 6 } & $\begin{array}{c}8 \mathrm{~g} / \mathrm{m}^{3}-\mathrm{HCl}, \\
2 \mathrm{~g} / \mathrm{m}^{3}-\mathrm{C}_{6} \mathrm{H}_{12} \\
\text { (Chloride-hexane) }\end{array}$ & & $\begin{array}{c}7 \mathrm{~g} / \mathrm{m}^{3} \\
\text { dry } \mathrm{HCl}\end{array}$ & $\begin{array}{c}7 \mathrm{~g} / \mathrm{m}^{3} 28 \% \\
\text { hydrochloricacid }\end{array}$ & $7 \mathrm{~g} / \mathrm{m}^{3} \mathrm{H}_{2} \mathrm{O}$ \\
\hline $\mathrm{Uz}-\mathrm{AD}-6$ & 15.4 (no) & & 11.6 & 24.8 & 9.8 \\
$\mathrm{Axstrap}-860$ & 16.3 (none) & & 11.9 & 22.9 & 9.5 \\
$\mathrm{MgAl}_{2} \mathrm{O}_{4}$ & 9.2 (traces) & & 3.6 & 7.7 & 2.8 \\
$\mathrm{MgAl}_{2} \mathrm{O}_{4}-\mathrm{NaOH}$ & 14.4 (none) & & 13.3 & 14.8 & 4.4 \\
$\gamma-\mathrm{Al}_{2} \mathrm{O}_{3}$ from pseudoboehmite & 11.5 (yes) & 9.3 & 17.4 & 5.6 \\
transformation & & & & & \\
\hline
\end{tabular}

*g Cl /100 g in circulation mode at $335 \mathrm{~K}$. 
As a consequence, in the IR spectrum of the gaseous reaction products, in addition to the bands of the model mixture, weak bands appeared within $850-550 \mathrm{~cm}^{-1}$, attributed to the formation of chlorhexane. Chlorinated oligomers appeared only in the adsorbed state on the $\gamma-\mathrm{Al}_{2} \mathrm{O}_{3}$ surface in the form of a clear band at $1270-1300 \mathrm{~cm}^{-1}$.

\section{Conclusions}

The studies of the features of the change in the chemical and phase composition of the alumina adsorbent, after the completion of the cycle of its operation in the process of removing chlorine-containing impurities from technological hydrogen, proved the expediency of its thermochemical modification with alkali metal hydroxides. The formation of highly basic aluminates of alkali metals and a satisfactory $\mathrm{HCl}$ adsorption capacity of the Uz-AD-6 adsorbent obtained by the complex processing of the used Axstrap-860 allow us to recommend it for reuse in the purification of hydrogen-containing gas at a naphtha reforming unit. Useful salts, including a coagulant for the purification of turbid water, were isolated from the liquid waste generated at the stage of removing chlorinecontaining compounds. Pseudoboehmite and an alumina adsorbent were obtained as a byproduct and this adsorbent is intended to remove droplet moisture from wet gases. The possibility of synthesis of magnesium-aluminum spinel resistant to thermal shock was found out, and it is suitable as a carrier for catalysts for steam conversion of hydrocarbons in accordance with its other characteristics.

\section{Acknowledgements}

This research was funded by Ministry of innovative development of the Republic of Uzbekistan, grant number FZ-2019-06066 and MUK2021-45.

\section{References}

[1] Yunusov, M.P., Nasullaev Kh.A., Gulomov Sh.T., Isaeva N.F., Mustafaev B.D., Rakhimjanov B.B., Khodjiev R.G. (2020). Analysis of the results of experimental sorbent for chloride compounds removal. Chemical Problems, 3(18), 366-375. DOI: 10.32737/2221-86882020-3-366-375

[2] Yunusov, M.P., Djalalova, Sh.B., Nasullaev, Kh.A., Isaeva, Sh., Mirzaeva, E.I. (2016). New catalytic systems for hydrofining and dearomatization processes of oil fractions. $\mathrm{Ca}$ talysis for Sustainable Energy, 3(1), 7-14. DOI: $10.1515 /$ cse-2016-0003
[3] Kurbanova, D.G., Teshabayev, Z.A., Nasullayev, H.A., Gulomov, Sh.T., Boymonov, R.M., Turdieva, D.P., Rakhimjonov, B.B. (2020). Processing of spent adsorbents and catalysts into protective layers for oil and gas processing. Vestniknauz, kimyo, 3(1), 263-266.

[4] Hongjun, Z., Mingliang, S., Huixin, W., Zeji, L., Hongbo, J. (2010). Modeling and simulation of moving bed reactor for catalytic naphtha reforming. Petroleum Science and Technology, 28, 667-676. D O I : $10.1080 / 10916460902804598$

[5] Kiryanov, D.I., Smolikov, M.D., Golinsky, D.V., Belopukhov, E.A., Zatolokina, E.V., Udras, I.E., White, A.S. (2018). History of development and current status of the catalytic reforming process in Russia. Experience of industrial production and operation of new reforming catalysts series PR. Rossiiskii Khimicheskii Zhurnal (Russian Chemistry Journal), 62(1-2), 12-23. DOI: 10.6060/rcj.2018621-2.2

[6] Rahimpour, M.R., Jafari, M., Iranshahi, D. (2013). Progress in catalytic naphtha reforming process: A review. Applied Energy, 109 79-93. DOI: 10.1016/j.apenergy.2013.03.080

[7] Chernyakova, E.S., Koksharov, A.G., Ivanchina, E.D., Yakupova, I.V. (2015). Heavy naphtha fractions $85-155^{\circ} \mathrm{c}$ recycling in the catalytic reforming industrial unit. Procedia Chemistry, $15, \quad 378-383$. D O I : 10.1016/j.proche.2015.10.060

[8] Rodríguez, M.A., Ancheyta, J. (2011). Detailed description of kinetic and reactor modeling for naphtha catalytic reforming. Fuel, $90, \quad 3492-3508$. D O I : 10.1016/j.fuel.2011.05.022

[9] Mazzieri, V.A., Grau, J.M., Vera, C.R., Yori, J.C., Parera, J.M., Pieck, C.L. (2005). Role of $\mathrm{Sn}$ in Pt-Re-Sn/ $/ \mathrm{Al}_{2} \mathrm{O}_{3}$-Cl catalysts for naphtha reforming. Catalysis Today, 107-108, 643650. DOI: 10.1016/j.cattod.2005.07.042

[10] Viswanadham, N.N., Kamble, R., Sharma, A., Kumar, M., Saxena, A.K. (2008). Effect of Re on product yields and deactivation patterns of naphtha reforming catalyst. Journal of Molecular Catalysis A: Chemical, 282, 74-79. DOI: 10.1016/j.molcata.2007.11.025

[11] Smolikov, M.D., Kiryanov, D.I., Kolmagorov, K.V., Udras, I.E., Zatolokina, E.V., White, A.S. (2013). Experience of industrial production and operation of new reforming catalysts PR-81 and ShPR-81. Catalysis in Industry, 6, 36-41. DOI: 10.1134/S2070050414010115

[12] Gurdin, V.I., Kovalenko, M.V., Krasiy, B.V., Mozhaiko, V.N., Sorokin, I.I. (2016). Highly stable reforming catalyst series $\mathrm{RB}$ in ball form. Refining and Petrochemicals, 10, 11-14. 
[13] Baghalha, M., Mohammadi, M., Ghorbanpour, A. (2010). Coke deposition mechanism on the pores of a commercial Pt-Re/c$\mathrm{Al}_{2} \mathrm{O}_{3}$ naphtha reforming catalyst. Fuel Processing Technology, 91, 714-722. DOI: 10.1016/j.fuproc.2010.02.002

[14] Ostrovskii, N.M. (2006). General equation for linear mechanisms of catalyst deactivation. Chemical Engineering Journal, 120, 73-82. DOI: $10.1016 /$ j.cej.2006.03.026

[15] Stijepovic, M.Z., Linke, P., Kijevcanin, M. (2010). Optimization approach for continuous catalytic regenerative reformer processes. Energy Fuels, 24, 1908-1916. DOI: $10.1021 /$ ef901193v

[16] Patent RU 2171710 B01 J 20/08, B01 J 20/04, published 10.08.2001

[17] Patent RU 2662540 C2 B01D 53/68, B01 J 20/02, published 26.07. 2018

[18] Patent RU 2219995 C2 B01 J 20/08, B01 J 53/68, 27.12.2003

[19] Shah, I.K., Pre, P., Alappat, B.J. (2013). Steam Regeneration of Adsorbents: An Experimental and Technical Review. Chemical Science Transactions, 2(4), 1078-1088. DOI: $10.7598 /$ cst2013.545

[20] Solodova, N.L., Cherkasova, E.I., Salakhov, I.I., Tutubalina, V.P. (2017). Hydrogen as an energy carrier and reagent. Technologies of its production. Problems of Power Engineering, 19, 11-12.

[21] Scha“del, B.T., Duisberg, M., Deutschmann, O. (2009). Steam reforming of methane, ethane, propane, butane, and natural Gas over a rhodium based catalyst. Catalysis Today, $\quad 142, \quad 42-51$. D O I : 10.1016/j.cattod.2009.01.008

[22] Fernandez, J.R., Abanades, J.C., Murillo, M. (2012). Modeling of sorption enhanced steam Methane reforming in an adiabatic fixed bed reactor. Chemical Engineering Science, 84, 111. DOI: $10.1016 /$ j.jece.2021.105863

[23] Astanovskiy, D.L., Astanovskiy, L.Z., Kustov, P.V. (2016). Energy-saving, environmentally friendly production of hydrogen from hydrocarbon raw materials. Neftegazokhimiya, 3, 10-16.

[24] Maestry, M., Vlachos, D.G., Beretta, A., Groppi, G., Tronconi, E. (2008). Steam and dry reforming of metahane on Rh: Microkinetic analysis and hierarchy of kinetic models. Journal of Catalysis, 259, 211-222. DOI: 10.1016/j.jcat.2008.08.008

[25] Pisarenko, E.V., Pisarenko, V.N. (2001). Energy- and resource-saving process of synthesis gas production from natural gas in methanol production. Theoretical Fundamentals of Chemical Technologies, 45(4), 371.
[26] Kuznetsov, V.V., Vitovsky, O.V., Gasenko, O.A. (2009). Methane steam reforming in an annular microchannel with $\mathrm{Rh} / \mathrm{Al}_{2} \mathrm{O}_{3}$ catalyst. Journal of Engineering Thermophysics, 18, 187-196. DOI: 10.1134/S1810232809030023

[27] Peighambardoust, S.J., Rowshanzamir, S., Amjadi, M. (2010). Review of the proton exchange membranes for fuel cell applications. International Journal of Hydrogen Energy, $35(17), \quad 9349-9384$. D O I : 10.1016/j.ijhydene.2010.05.017

[28] Snytnikov, P.V., Badmaev, S.D., Volkova, G.G., Potemkin, D.I., Zyryanova, M.M., Belyaev, V.D., Sobyanin, V.A. (2012). Catalysts for hydrogen production in a multifuel processor by methanol, dimethyl ether and bioethanol steam reforming for fuel cell applications. International Journal of Hydrogen Energy, 37(21), 16388-16396. DOI: 10.1016/j.ijhydene.2012.02.116

[29] Zyryanova, M., Badmaev, S.D., Belyaev, V.D., Amosov, Y.I.,. Snytnikov, P.V, Kirillov, V.A., Sobyanin, V.A. (2013). Catalytic conversion of hydrocarbon raw materials into fuel for power plants. Catalysis in Industry, 3, 22-27. DOI: 10.1134/S2070050413040107

[30] Molodozhenyuk, T.B., Vorobyov, V.N., Ishanova, L.R., Razikov, K.Kh. (1984). Study of destructive-epitaxial and thermal transformations in the $\mathrm{MgO}-\mathrm{Al}_{2} \mathrm{O}_{3}-\mathrm{H}_{2} \mathrm{O}$ system. Journal of Applied Chemistry, 7, 1454-1459.

[31] Mustafayev, B.D. Turdiyeva, D.P., Kurbanova, D.G., Rakhimjonov, B.B., Isayeva, N.F., Satarova, Sh.G. (2020). Effect of aluminum oxide precursor on the formation of sodium aluminates in the adsorbent composition. Ilm-fan va Innovatsion Rivozhlanish, 5, 124134.

[32] Ledovskaya, E.G., Gabelkov, S.V., Litvinenko, L.M., Logvinkov, D.S., Mironova, A.G., Odeichuk, M.A., Poltavtsev, N.S., Tarasov, R.V. (2006). Low temperature synthesis of magnesium-aluminum spinel. Voprosy Atomnoj Nauki i Tekhniki, 1, 160-163.

[33] Domanski, D., Urretavizcaya, G., Castro, F.J., Gennari, F.C. (2004). Mechanochemical synthesis of magnesium aluminate spinel powder at room temperature. Journal of the American Ceramic Society, 87(11), 20202024 . DO I : $10.1111 / \mathrm{j} .1151$ 2916.2004.tb06354.x

[34] Ishimaru, M., Hirotsu, Y., AfanasyevCharkin, I.V., Sickafus, K.E. (2002). Atomistic structures of metastable and amorphous phases in ion-irradiated magnesium aluminate spinel. Journal of Physics: Condensed Matter, 14(6), 1237-1247. DOI: 10.1088/0953$8984 / 14 / 6 / 311$ 
[35] Senina M.O., Lemeshev, D.O. (2016). Ways of synthesizing powders of magnesium aluminate spinel for obtaining optically transparent ceramics (review). Advances in Chemistry and Chemical Technology, 7, 101-103. DOI: 10.1007/s10717-018-9994-8

[36] Ganesh, J.A. (2013). Review on magnesium aluminate $\left(\mathrm{MgAl}_{2} \mathrm{O}_{4}\right)$ spinel: synthesis, processing and applications. International Materials Reviews, 115(16), 63-112. DOI: 10.1179/1743280412Y.0000000001
[37] Yunusov, M.P., Saidaxmedov, Sh.M., Djalalova, Sh.B., Nasullaev, Kh.A., Gulyamov, Sh.T., Isaeva, N.F., Mirzaeva, E.I. (2015). Synthesis and Study of Ni-Mo-Co Catalysts for Hydroprocessing of Oil Fractions. Catalysis for Sustainable Energy, 2(1), 43-56. DOI: $10.1515 /$ cse-2015-0003

[38] Isayeva, N.F., Jalalova, Sh.B. (2012). Technology of preparation of carriers on the basis of aluminum hydroxide of different shelf life, Uzbek Journal of Oil and Gas, 1, 27-31. 